\title{
The Cross-Cultural Knowledge Sharing Challenge: An Investigation of the Co-location Strategy in Software Development Offshoring
}

\author{
John Stouby Persson \\ Department of Computer Science, Aalborg University, Aalborg, Denmark \\ johnecs.aau.dk
}

\begin{abstract}
Cross-cultural offshoring in software development challenges effective knowledge sharing. While research has suggested temporarily co-locating participants to address this challenge, few studies are available on what knowledge sharing practices emerge over time when co-locating cross-cultural software developers. This paper presents a longitudinal case study of an offshoring project with co-location of Indian and Danish software developers for $10^{1 / 2}$ months. A community-of-practice $(\mathrm{CoP})$ analysis is offered of what knowledge sharing practices emerge over time and how these where facilitated. The study supports previous studies' suggestion of co-location in offshoring for helping cross-cultural knowledge sharing. However, the short initial period of co-location suggested in these studies, was insufficient for achieving knowledge sharing practices indicating a CoP. In conjunction with a longer period of colocation four facilitators of cross-cultural knowledge sharing were shared office, shared responsibility for tasks and problems, shared prioritization of team spirit, and a champion of social integration.
\end{abstract}

Keywords: cross-cultural software projects, offshore outsourcing, knowledge sharing, communities-of-practice, longitudinal case study.

\section{Introduction}

The substantial research knowledge base on information technology and systems accumulated over decades does not prevent the persistent failures in both public and private enterprises. One explanation is the challenge of sharing knowledge such that it becomes embedded in the working practices of the involved practitioners. The knowledge sharing challenge is present throughout most aspects of information technology and systems development in and across organizations. The challenge can even be further exacerbated by cultural diversity when crossing not only organizational but also national boundaries. Offshoring in software development is a setting where the cross-cultural knowledge sharing challenge has a very persistent presence. With a history of numerous failures, many research efforts have investigated risks particular to offshoring and distribution (Iacovou \& Nakatsu, 2008; Lamersdorf et al., 2012; Persson \& Mathiassen, 2010; Singh \& Nigam, 2012). Knowledge sharing is one of the key challenges in software development with offshoring that is further 
exacerbated by different national cultures (Boden et al., 2012; Dibbern et al., 2008; Nakatsu \& Iacovou, 2009; Persson et al., 2009). A general suggestion to alleviate risks related to offshoring in software development is co-location of developers. Previous research suggest that liaisons between sites address the risks related to knowledge management and cultural diversity in distributed software development projects (Persson et al., 2009). A recent study of knowledge sharing practices and the impact of cultural factors found that spending time at the other site in software development offshoring, is very good (Boden et al., 2012). In global software development, faceto-face meetings, temporal co-location, and exchange visits are best practices with benefits such as trust, cohesiveness, and effective teamwork but also constrained by extra costs (Šmite et al., 2010). While these suggestions has also been argued for virtual work in general, other research has found that teams composed of distributed members can perform effectively without ever meeting face-to-face (Watson-Manheim et al., 2012). However, co-location of project participants is still an often-reoccurring suggestion for addressing the knowledge sharing challenge in the offshore software development with cross-cultural relations. The extent, to which this suggestion of co-location should be taken, has been given little attention in the above literature. Thus, a longitudinal case study has been conducted to investigate the following research question: When co-locating cross-cultural software developers, what knowledge sharing practices may emerge over time and how can such practices be facilitated?

The research question was investigated through a case where a financial company engaged a large amount of software developers from an Indian outsourcing provider and collocated them with their own developers in Denmark. Based on a Communitiesof-Practice $(\mathrm{CoP})$ perspective on knowledge sharing, an analysis is conducted of what practices emerged over time and how they were facilitated. The following sections present the literature on cultural diversity and offshoring (2) and CoP (3). Followed by the case study research approach (4) and findings (5) of knowledge sharing practices in a collocated cross-cultural software project. The contribution and implications of these findings are discussed (6) followed by the conclusion (7).

\section{Cultural Diversity and Offshoring in Software Development}

Culturally and geographically distributed collaborators in software development projects or organizations have different conceptualizations. Three common conceptualizations are 1) virtual teams (Bergiel et al., 2008; Gibson \& Gibbs, 2006), 2) global software development (Damian \& Moitra, 2006; Mishra \& Mishra, 2011), and 3) offshore outsourcing (Doh, 2005; Nakatsu \& Iacovou, 2009). Indicated by several literature studies in different research fields, virtual teams is a widespread and frequently used conceptualization (Persson, 2010). The majority of studies see virtual teams as functioning teams that rely on technology-mediated communication while crossing several different boundaries (Martins et al., 2004). Commonly-noted boundaries are geographic, time, and organizational dispersion, while additional characteristics are electronic dependence, structural dynamism, and national diversity(Gibson \& Gibbs, 2006; Martins et al., 2004; Powell et al., 2004). The term "team" suggests groups displaying high levels of interdependency and integration (Powell et al., 2004). However, virtual teams are often assembled from 
different organizations via outsourcing, or through joint ventures crossing organizational boundaries (Martins et al., 2004; Zigurs, 2003). A virtual team perspective on collaboration has also been adopted for software development with offshore outsourcing (Persson, 2010; Siakas \& Siakas, 2008). Offshore outsourcing involves cross-organizational transactions by the use of external agents to perform one or more organizational activities (Dibbern et al., 2004) crossing national borders. This can apply to everything from the use of contract programmers to third-party facilities management. Offshore outsourcing arrangements can include a virtual team setting, pursuing high levels of interdependency and integration, while other arrangements go in opposite directions pursuing high levels of independence (Dibbern et al., 2004; Kaiser \& Hawk, 2004; Siakas \& Siakas, 2008).

The participants in offshore software development may not share language, traditions, or organizational culture, which makes knowledge sharing very difficult. Language barriers are typically present in cross-national projects when sites and participants do not share a common native language or norms of communication resulting in misinterpretations and un-conveyed information (Krishna et al., 2004; Sarker \& Sahay, 2004). Overall, it takes more time and effort to communicate effectively in offshore projects (Iacovou \& Nakatsu, 2008). However, studies have also shown successful knowledge sharing and collaboration among geographically and culturally distributed software developers through information and communication technologies (Persson et al., 2012; Yalaho \& Nahar, 2010). Differences in work culture, team behavior, or organizational culture may also lead to difficulties (Connaughton \& Shuffler, 2007; Nakatsu \& Iacovou, 2009; Persson, 2010), that can be caused by divergence between sites, in balancing collectivism and individualism, perception of authority and hierarchy, and planning and punctuality (Herbsleb \& Moitra, 2001; Krishna et al., 2004). This may lead to decreased conflict-handling, lower efficiency, or even paralyze the software project. In general, when projects are distributed across time, space, and culture, it is difficult to obtain the same level of group cohesion and knowledge sharing expected in collocated teams (Sakthivel, 2005). One suggestion for addressing the risks in offshore software development is working face-to-face (Sakthivel, 2007). Working face-to-face for limited periods of time in global or offshore software development has been suggested by numerous studies (Boden et al., 2012; Kotlarsky \& Oshri, 2005; Krishna et al., 2004; Šmite et al., 2010). This may include the use 'cultural bridging' staff with people rooted in both cultures or locals as on-site workers at the supplier (Krishna et al., 2004), exchange visits (Šmite et al., 2010), or the use of liaisons between sites to address the risks related to knowledge management and cultural diversity (Persson et al., 2009; Persson \& Mathiassen, 2010). Boden et al. (2012) found in their study of knowledge sharing practices and the impact of cultural factors in offshore software development, that spending time at the other site is very good. While, the suggested best practices in face-to-face meetings, temporal co-location, and exchange visits can give rise to benefits in trust, cohesiveness, and effective teamwork it is constrained by the extra costs (Šmite et al., 2010). In general, it has been argued that in order to avoid project failures that the onshore and offshore teams from the vendor and client sides should work as an integrated project team (Philip et al., 2012).

While numerous studies have suggested co-location for alleviating knowledge sharing difficulties in cross-cultural and offshored software development, there is an apparent need for in-depth studies of how knowledge sharing practices can emerge 
with co-location. This may help managers make more informed decisions on how and to what extend co-location can be used for alleviating the risks associated with crosscultural knowledge sharing in offshore software development. The following section presents the $\mathrm{CoP}$ framework for understanding knowledge sharing in practice.

\section{Communities of Practice}

Software development in and across organizations requires extensive knowledge sharing, that can be conceptualized as collective learning.

... collective learning results in practices that reflect both the pursuit of our enterprises and the attendant social relations. These practices are thus the property of a kind of community created over time by the sustained pursuit of a shared enterprise. It makes sense, therefore, to call these kinds of communities communities of practice. (Wenger, 1998 p.45)

The CoP conceptualization has been used extensively for explaining or cultivating knowledge sharing in distributed settings (Hildreth et al., 2000; Kimble \& Hildreth, 2005; Wenger et al., 2002) also called virtual communities of practice (Ardichvili, 2008; Dubé et al., 2006). However, the influential works introducing CoP (Brown \& Duguid, 1991; Lave \& Wenger, 1991; Wenger, 1998; Wenger et al., 2002) conceptualize it differently (Cox, 2005). These works differs markedly in their conceptualizations of community, learning, power and change, diversity, and informality, for instance is the concept of community presented in the following ways (Cox, 2005):

- A group of people involved in a coherent craft or practice, e.g. butchers OR Not a neatly group at all (Lave \& Wenger, 1991).

- An informal group of workers doing the same or similar jobs (Brown \& Duguid, 1991).

- A set of social relations and meanings that grow up around a work process when it is appropriated by participants (Wenger, 1998).

- An informal club or Special Interest Group inside an organization, set up explicitly to allow collective learning and cultivated by management action (Wenger et al., 2002).

This study investigates what knowledge sharing practices emerge over time when colocating a project's cross-cultural software developers. Thus, Wenger's (1998) focus in the third bullet above on social relations and meanings (knowledge sharing) that grow up around a work process (software development project) when it is appropriated by participants (Indian and Danish Software developers), is adopted instead of his more recent work in the fourth bullet above (Wenger et al., 2002). Cox summarize Wengers (1998) definition of $\mathrm{CoP}$ as "a group that coheres through 'mutual engagement' on an 'indigenous' (or appropriated) enterprise, and creating a common repertoire" (Cox, 2005). Wenger (1998) associates community with practice that is the source of coherence for a community. He proposes three dimensions of the relation including, mutual engagement, joint enterprise, and shared repertoire (Fig. 1). 


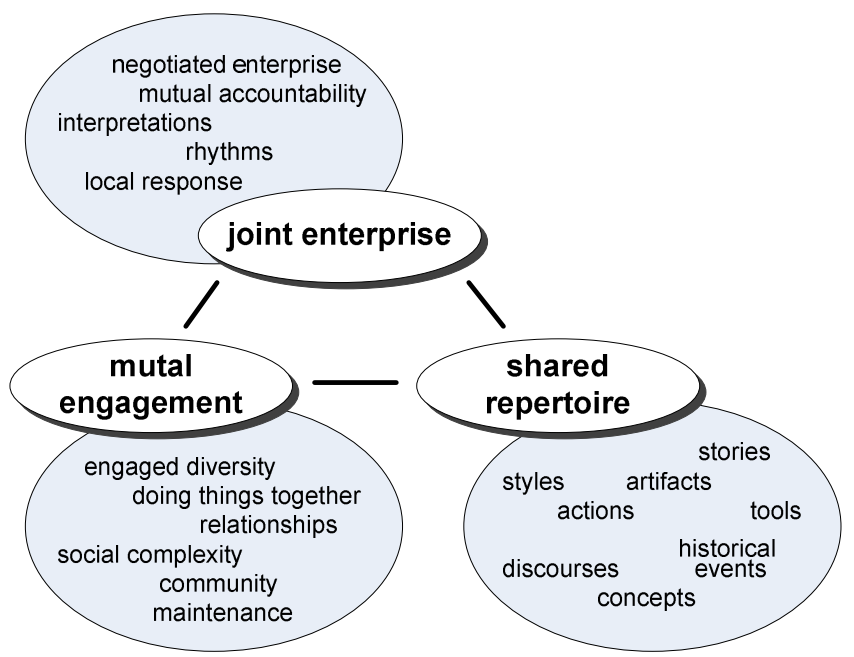

Fig. 1. Dimensions of practice as the property of a community (Wenger, 1998 p.73)

Wenger (1998) presents 14 indicators of CoP (Table 1), that show an emphasis of close relations created by sustained mutual engagement opposed to the less tight knit community relations in his following work (Wenger et al., 2002). While these indicators can be a strong aid in clarifying the nature of $\mathrm{CoP}$, they have not been widely referenced by subsequent researchers (Cox, 2005). These indictors serve as the analytical framework for identifying knowledge sharing practices emerging over time in the investigated cross-cultural software project.

Table 1. Indicators of CoP (Wenger, 1998 p.125-126)

\begin{tabular}{l}
\hline 1) Sustained mutual relationships - harmonious or conflictual \\
\hline 2) Shared ways of engaging in doing things together \\
\hline 3) The rapid flow of information and propagation of innovation \\
\hline $\begin{array}{l}\text { 4) Absence of introductory preambles, as if conversations and interactions were merely the } \\
\text { continuation of an ongoing process }\end{array}$ \\
\hline 5) Very quick setup of a problem to be discussed \\
\hline 6) Substantial overlap in participants' descriptions of who belongs \\
\hline 7) Knowing what others know, what they can do, and how they can contribute to an enter- \\
prise \\
\hline 8) Mutually defining identities \\
\hline 9) The ability to assess the appropriateness of actions and products \\
\hline 10) Specific tools, representations, and other artifacts \\
\hline 11) Local lore, shared stories, inside jokes, knowing laughter \\
\hline 12) Jargon and shortcuts to communication as well as the ease of producing new ones \\
\hline 13) Certain styles recognized as displaying membership \\
\hline 14) A shared discourse reflecting a certain perspective on the world \\
\hline
\end{tabular}


The following section presents the investigated case, the date collection, and how the content of these data was analyzed for any supportive or opposing findings in relation each of the 14 indicators of $\mathrm{CoP}$.

\section{$4 \quad$ Research Approach}

The research question was investigated through a longitudinal case study, exploiting that "knowledge sharing practices need to be studied in context and longitudinally" when dealing with knowledge sharing and cultural diversity in software development with offshoring (Boden et al., 2012). The adopted case study approach was in the terms of Cavaye (1996) single case with use of qualitative data for discovery based on an interpretive epistemology. Interpretive research allow investigation of knowledge sharing and $\mathrm{CoP}$ in its organizational and cross-cultural context as socially constructed and thus open to several interpretations by organizational actors but also to the researcher (Klein \& Myers, 1999; Walsham, 2006).

\subsection{The Case}

The case was a software development project in a large financial company in northern Europe with a history of national mergers and acquiring companies in neighboring countries. Each acquisition requires a significant effort from the company's IT division, implementing the standard IT platform as quickly as possible in all new branches to achieve economies of scale. The responsibility for the IT platform resides at the company's headquarters. However, some acquired companies have their own IT departments that became engaged in making the shared IT platform adhere to specific financial software system requirements in their respective countries. The company's most recent acquisition is different from previous acquisitions. It's significantly larger, has a sophisticated IT platform, and is located in a country with a different language tradition from the dominant language within the company. Previous acquisitions were smaller, had an inferior IT platform, and involved a language tradition similar to or easily understandable to the employees of the company. This implementation project of the company's standard IT platform had more than 500 participants and a strict one-year deadline. The project required a large number of software developers and the company engaged an Indian software outsourcing provider. The company had limited experience with offshore outsourcing but had engaged an Indian outsourcing provider experienced in outsourcing relations with financial companies. The large integration project consisted of numerous subprojects associated with different departments of the company's IT division. This case study was initiated through contact with a department manager who would supply the project managers and developers for the subprojects related to his department. Participants from the company's internal consultancy organization, responsible for both locally recruited employees and the consultants from the Indian outsourcing provider, would also populate these subprojects. The Indian consultants available for the department's subprojects were placed in a single subproject and collocated with the Danish participants 
at the department offices in Denmark. This subproject with the Indian participants was the focus of this case study. The sub-project manager had two rather different tasks, one related to the company's telephone system and the other to the system managing payment agreements. Thus in practice, the subproject had two subprojects working on these tasks. Eleven people were involved in this subproject, including a project manager, a business developer, a test coordinator who left the company and was replaced by one of the developers, and eight developers. Three of the developers were Indian consultants, while the developer who replaced the test coordinator was a newly hired employee from the consultancy organization within the company.

The sub-project delivered on the two tasks on time without a high level of last minute pressure and with only one reported error that was easily amendable. Following delivery, the subproject participants spent most of their time on documentation and helping other subprojects. Other sub-projects of the integration project also had extended co-location of Indian developers, but some of these projects experienced limited success in making them valuable contributing members. The overall integration project was implemented at the acquired company on the initially set date. However, the implementation was followed by numerous errors and a large amount of negative attention from the news media in the country of the acquired company. Within the company, the integration project was initially perceived as successful. However, the negative press eventually influenced this view. Over time, the news media attention is now more positive to the company and the integration project. However, the integration project cannot easily be labeled as one of the grand successes or failures in IT, even though different stakeholders have attempted to label the project as either a big success or failure.

\subsection{Data Collection and Analysis}

The data collection spanned 1 year and 6 months (Fig. 2) and included various documents and audio-recorded meetings, observations, and interviews for understanding the context of the subproject with collocated Indian developers. The subproject was investigated through six rounds of semi-structured interviews with all available participants (Fig. 2) resulting in 56 audio-recorded interviews.

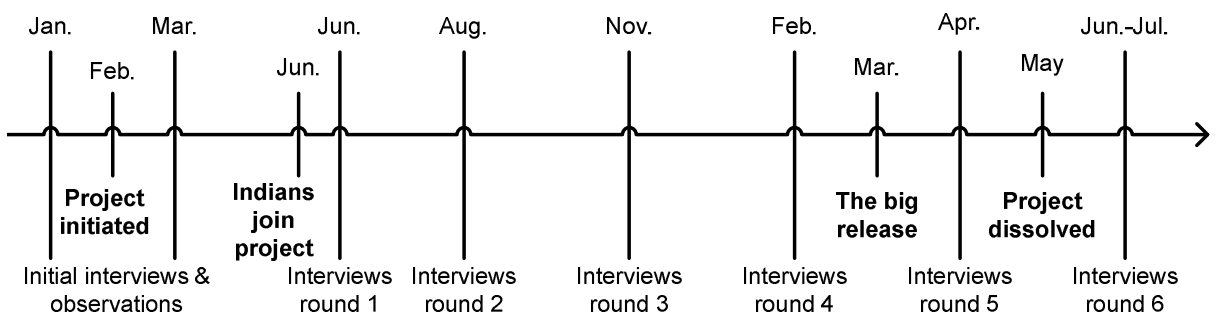

Fig. 2. Timeline of project 
The author conducted the six rounds of interviews with an interview guide based on Wenger's (1998) conceptualization of CoP. The interview guide included questions to the activities on an ordinary day, use of tools, collaborators, collegial relations, professional inspiration, current challenges, and changes since last interview. The interviews were planned to take $1 / 2$-hour pr. person but some were longer while others were shorter. The first round of interviews was conducted two weeks after the first Indian developer arrived while they went back to India few days after the fifth round of interviews 10 months later. The knowledge sharing practices revealed through analysis of the first ( 9 interviews lasting $4 \mathrm{~h} 7 \mathrm{~m}$ ) and fifth ( 9 interviews $4 \mathrm{~h} 4 \mathrm{~m}$ ) rounds (Fig. 2), is the primary focus of this paper.

The author conducted a content analysis of the audio-recordings of the first and fifth round of interviews using Nvivo 8. A content analysis involves observing repeating themes and categorizing them using a coding system elicited in a grounded way (built up from the data) or from some external source (in this case the indicators of $\mathrm{CoP}$ presented in the theory section, Table 1). The content analysis was qualitative as the indicators of $\mathrm{CoP}$ were studied in their location in the source audio-recording, where the addition of context can help to identify additional relevant factors. The analysis software NVivo 8 was used for the code-based analysis, distinguishing between theoretical constructs (Wengers (1998) indicators of CoP) and descriptive codes based on the language of the interviewees (Fielding \& Lee, 1998).

\section{$5 \quad$ Findings}

The analysis of the interviews two weeks after the Indians arrival and two days before their departure resulted in 208 coded indications of CoP with 86 opposing and 112 supportive findings. The arrival interviews had $99 \mathrm{CoP}$ indicators, while the departure interviews had $109 \mathrm{CoP}$ indicators (Table 2).

Table 2 summarizes the supportive and opposing findings indicating CoP from interviews with the project manager, Indian developers, and Danish developers. An example of this coding, with the descriptive code "Indians are colleagues, but the language is difficult", is part of a Danish developer's response to the question of whether he considers the Indians his colleagues:

"I share an office with one... I think we try to include him (the Indian developer) and he tries to be included. There are off course some language issues. Sometimes we want to discuss something with the person next to you in Danish because it is difficult to do in English. Then he is excluded because we talk Danish in some situations. But, when we have had a discussion, we sometimes follow up with a summary to him- saying we have just discussed this and this, what do you think of that?" (DD, arrival)

The interpretation of this quote was that the Danish developer described the Indian as belonging ( $\mathrm{CoP}$ indicator 6) and that they have a sustained mutual relationship (CoP indicator 1). However, the quote also showed opposition to rapid flow of information (CoP indicator 3), a very quick setup of problems to be discussed (CoP indicator 5), and shortcuts to communication (CoP indicator 12). Thus, this quote was coded with 
Table 2. Indications of $\mathrm{CoP}$ from the project manager (PM), Indian Developers (IDs) and, Danish Developers (DDs) (V: Supportive, X: Opposing, !: Mixed, "empty field": No findings)

\begin{tabular}{|c|c|c|c|c|c|c|}
\hline \multirow[t]{2}{*}{ Indicators of $\mathrm{CoP}$} & \multicolumn{3}{|c|}{$\begin{array}{l}\text { Two weeks after } \\
\text { Indians arrival }\end{array}$} & \multicolumn{3}{|c|}{$\begin{array}{l}10 \text { months later, } \\
\text { two days before } \\
\text { Indians departure }\end{array}$} \\
\hline & $\mathrm{PM}$ & IDs & DDs & PM & IDs & DDs \\
\hline $\begin{array}{l}\text { 1) Sustained mutual relationships - harmonious } \\
\text { or conflictual }\end{array}$ & $V_{1}$ & $X_{1}$ & $! 5 / 2$ & $!_{1 / 1}$ & $V_{4}$ & $! 7 / 7$ \\
\hline $\begin{array}{l}\text { 2) Shared ways of engaging in doing things } \\
\text { together }\end{array}$ & $X_{3}$ & $X_{5}$ & $X_{6}$ & $V_{2}$ & $V_{5}$ & $V_{7}$ \\
\hline $\begin{array}{l}\text { 3) The rapid flow of information and propaga- } \\
\text { tion of innovation }\end{array}$ & $X_{3}$ & & $X_{7}$ & $V_{2}$ & & $V_{1}$ \\
\hline $\begin{array}{l}\text { 4) Absence of introductory preambles, as if } \\
\text { conversations and interactions were merely the } \\
\text { continuation of an ongoing process }\end{array}$ & $\mathrm{X}_{1}$ & $X_{1}$ & & & & $\mathbf{V}_{1}$ \\
\hline $\begin{array}{l}\text { 5) Very quick setup of a problem to be dis- } \\
\text { cussed }\end{array}$ & $X_{2}$ & $X_{5}$ & $X_{2}$ & $V_{2}$ & $V_{1}$ & $V_{3}$ \\
\hline $\begin{array}{l}\text { 6) Substantial overlap in participants' descrip- } \\
\text { tions of who belongs }\end{array}$ & $V_{1}$ & $V_{2}$ & $! 7 / 2$ & & $V_{1}$ & $!_{6 / 3}$ \\
\hline $\begin{array}{l}\text { 7) Knowing what others know, what they can } \\
\text { do, and how they can contribute to an enter- } \\
\text { prise }\end{array}$ & $\mathrm{X}_{1}$ & & $\mathrm{X}_{1}$ & & $V_{2}$ & $\mathbf{V}_{6}$ \\
\hline 8) Mutually defining identities & $\mathrm{X}_{1}$ & $\mathrm{X}_{1}$ & $X_{5}$ & $V_{2}$ & $V_{3}$ & $V_{7}$ \\
\hline $\begin{array}{l}\text { 9) The ability to assess the appropriateness of } \\
\text { actions and products }\end{array}$ & $X_{2}$ & $\mathrm{X}_{1}$ & & $V_{2}$ & & $V_{3}$ \\
\hline $\begin{array}{l}\text { 10) Specific tools, representations, and other } \\
\text { artifacts }\end{array}$ & & $\mathrm{X}_{4}$ & $X_{3}$ & & $V_{1}$ & $V_{1}$ \\
\hline $\begin{array}{l}\text { 11) Local lore, shared stories, inside jokes, } \\
\text { knowing laughter }\end{array}$ & & & $X_{2}$ & $V_{1}$ & $V_{4}$ & $V_{7}$ \\
\hline $\begin{array}{l}\text { 12) Jargon and shortcuts to communication as } \\
\text { well as the ease of producing new ones }\end{array}$ & $X_{3}$ & & $\mathrm{X}_{4}$ & $V_{1}$ & $V_{1}$ & \\
\hline $\begin{array}{l}\text { 13) Certain styles recognized as displaying } \\
\text { membership }\end{array}$ & $X_{1}$ & $x_{2}$ & $X_{3}$ & & $V_{1}$ & $V_{4}$ \\
\hline $\begin{array}{l}\text { 14) A shared discourse reflecting a certain } \\
\text { perspective on the world. }\end{array}$ & $X_{1}$ & $X_{1}$ & $x_{2}$ & $V_{2}$ & $V_{3}$ & $V_{6}$ \\
\hline
\end{tabular}

two supportive and three opposing indicators of CoP. Some of the $14 \mathrm{CoP}$ indicators had neither supportive nor opposing findings, while two of the indicators had both supportive and opposing findings in the interview or interview grouping. Most of the statements reflecting $\mathrm{CoP}$ involved more than one of the 14 indicators presented in Table 2. In total, 73 statements reflecting CoP was coded with a description based on the language of the interviewees. Of the 73 statements, 25 had only opposing indicators, 36 had only supportive indicators, while 12 had both opposing and supportive indicators (as the example presented above). 


\subsection{Two Weeks After the Indians Arrival}

The nine interviews after the Indians arrival included the project manager, two Indian developers, and six Danish developers and a test coordinator. The analysis revealed 99 indicators of CoP of which 75 were opposing and 24 were supportive (Table 2). The second CoP indicator, "shared ways of engaging in doing things together" was with 14 opposing findings from all but one Danish developer the most frequently identified. The project manager shows an example of differences in ways of engagement between the Danish and Indian developers in this quote:

“... I have introduced project meetings every two weeks; I call them "buzz meetings"... I have not invited the Indians because people sometimes need to talk to me in Danish..." (PM, arrival)

In this way, the project manager established distinct engagement practices for the Indian and Danish developers. One Indian also mentioned that he usually eats lunch with the 10-15 other Indians participating in different projects at different departments and rarely with the other project participants. In addition, does his description of a regular workday differ from that of the Danes'; by being more individualized work on tasks from a schedule defined by the Danish project participants. These distinctive practices between the Indians and Danes also appeared in the use of software development tools (CoP indicator 10):

“... at present in the specification phase I am using RSM [IBM Rational Software Modeler]... it's a customized version for *the company*... *name of the other Indian project participant* is also making use of it, the others are also supposed to use it, but since it is a new tool they need some training... they do the work they are comfortable with, and I do the work I am comfortable with..." (ID, arrival)

The quote shows the Indian developers bring knowledge to the project not held by the other participants. The Indians are not sharing this knowledge through mutual engagement with the Danish developers; instead, it is used for a division of labor. However, the Danes valued the Indians held this knowledge and they used it later to present the Indian developers as valuable project participants. The Danes did also reveal resistance to the inclusion of the Indian developers:

“... I think that we all would prefer to avoid having the Indians because it takes time

and nobody has time..." (DD, arrival)

Not all the project participants shared this resistance towards the Indian developers. At the time of their arrival most of the participants described the Indians as belonging and the Indians also described themselves as belonging (CoP indicator 6). The project manager and some of the Danish developers also emphasized the current and future mutual relationship between them and the Indians (CoP indicator 1).

\subsection{Two days before the Indians departure}

The nine interviews two days before the Indians departure after $101 / 2$ months of colocation included the project manager, three Indian developers, and five Danish developers and a test coordinator. The analysis revealed 109 indicators of $\mathrm{CoP}$ of which 98 were supportive and 11 were opposing (Table 2). In the interviews close to the Indians departure, the second $\mathrm{CoP}$ indicator "shared ways of engaging in doing things 
together" was also one of the most frequently identified but now with 14 supportive findings. This time, the project manager shows an example of a shared way of engaging both the Danish and Indian developers in the project planning with small responsive meetings:

“... we did not make a plan, saying this is the plan for the next three months, you continuously relate to it and if it is drifting, then we have a small meeting in payment agreement [subproject] to deal with it..." (PM, departure)

In the above quote, the project manager is inclusive of the Indians in the term we while mainly distinguishing between project participants based on what subproject they belong. Thus, they have a joint enterprise but also high mutual engagement between the two nationalities, as stated by an Indian developer:

“... They feel we are one among them, not separated by you being from India. Their treatment brought us close. Our thoughts are similar, that is the thing, that made us more close. We used to make fun in our rooms when we are working and we used to laugh together and that gives a better relation..." (ID, departure)

The quote show their mutual engagement have a shared repertoire in laughing together ( $\mathrm{CoP}$ indicator 11) and an inclusive treatment of the Indian developers as members (CoP indicator 13) with similar ways of thinking (CoP indicator 14). The Danish developers mentioned elements of a mutual engagement with a shared repertoire in their joint enterprise, such as a good team spirit, also mentioned by the Indian developers:

“... There is a good team spirit... Off course, we know the Indians are going home now, so we need to get something out of them before they disappear. We have been involved in most of the things they have been doing, but some of the details are unknown to us..." (DD, departure)

While the good team spirit show the Indians was seen as belonging to the project (CoP indicator 6), this Danish developer also know what they have contributed to their joint enterprise (CoP indicator 7). Knowing this, there was a concern related to the end of the collocated sustained mutual relationship with the Indian developers (CoP indicator 1).

\subsection{Change in Knowledge Sharing Practices}

The 10 months of collocated software development in addition to the two initial weeks, resulted in considerable changed knowledge sharing practices when comparing CoP indicators (Table 2). All of the 14 knowledge sharing practices indicating CoP had emerged over the 10 months of co-location in the cross-cultural software project. The following four knowledge sharing facilitators, was synthesized from the descriptive codes attached to the indicators of $\mathrm{CoP}$ in the interviews two days before the Indians departure. The Danish project participants viewed these facilitators as distinguishing their successful integration of Indians compared to the other subprojects. These other subproject had limited success in making the Indians valuable contributing members, despite of similar extended co-location. The four knowledge sharing facilitators are exemplified with a quote from the interviews: 


\begin{tabular}{|c|c|}
\hline Shared office & $\begin{array}{c}\text { "... they have been sitting close together, that is what everybody } \\
\text { says, it would not have been the same, if they have been sitting in an } \\
\text { entirely different office..." (PM, departure) }\end{array}$ \\
\hline $\begin{array}{l}\text { Shared responsi- } \\
\text { bility for tasks and } \\
\text { problems }\end{array}$ & $\begin{array}{l}\text { "... once *name of Danish developer* felt stressed and asked for } \\
\text { help, the others working on lower priority tasks immediately offered } \\
\text { their help...it helps a lot that I am not alone with a task, it is a group } \\
\text { assignment we are doing..." (DD, departure) }\end{array}$ \\
\hline $\begin{array}{l}\text { Shared prioritiza- } \\
\text { tion of team spirit }\end{array}$ & $\begin{array}{l}\text { "I think we all wanted to create a good working relationship and we } \\
\text { all know the importance of team spirit." (DD, departure) }\end{array}$ \\
\hline $\begin{array}{l}\text { A champion of so- } \\
\text { cial integration }\end{array}$ & $\begin{array}{c}\text { "... One of the reasons for the high integration of our Indians in our } \\
\text { project is *name of ID* who arrived first... it is rare to see Indians } \\
\text { eating lunch with Danes, but he often did that from day one, and } \\
\text { influenced the other Indian project participants in that way... he tries } \\
\text { to learn Danish and he is good at being extrovert... he did not come } \\
\text { just to sit with the other Indians ..." (DD, departure) }\end{array}$ \\
\hline
\end{tabular}

\section{Discussion}

The cross-cultural knowledge sharing challenge and the co-location strategy was investigated in software development offshoring with the research question "When colocating cross-cultural software developers, what knowledge sharing practices may emerge over time and how can such practices be facilitated?". This study show that with co-location of a project's cross-cultural software developers, knowledge sharing practices covering all of Wenger's (1998) 14 indicators of CoP can emerge, but not after only two weeks of co-location. These knowledge sharing practices was according to the project participants facilitated differently to projects with less successful use of co-location by: 1) shared office, 2) shared responsibility for tasks and problems, 3) shared prioritization of team spirit, and 4) a champion of social integration.

The study contributes to our understanding of the cross-cultural knowledge sharing challenge in the context of software development offshoring (Dibbern et al., 2008; Nakatsu \& Iacovou, 2009; Persson et al., 2009). Investigating the suggestion of working face-to-face proposed by numerous studies of global and offshore software development (Boden et al., 2012; Kotlarsky \& Oshri, 2005; Krishna et al., 2004; Šmite et al., 2010). The study supports the potential value of co-location for risk alleviation (Persson \& Mathiassen, 2010; Sakthivel, 2007), but also extend these studies by showing how longer periods of co-location can support alleviation of the knowledge sharing challenge in cross-cultural offshoring. This investigation supports the Boden et al. (2012) study of knowledge sharing practices and the impact of cultural factors in offshore software development, in their finding that spending time at the other site is very good. However, this study adds, that an extended period of co-location may benefit cross-cultural knowledge sharing more substantially. This is based on the finding that knowledge sharing practices reflected in Wenger's (1998) indicators of CoP was not achieved in the first two weeks of co-location. Thus, this study extends the research suggesting face-to-face work for supporting cross-cultural knowledge sharing 
(Boden et al., 2012; Kotlarsky \& Oshri, 2005; Krishna et al., 2004; Šmite et al., 2010) by showing that shorter periods of co-location may only have limited effect on achieving knowledge sharing practices that indicate a CoP. Yet the achievement of a CoP may be critical to the success of software development offshoring. This is supported by Philip et al. (2012) claiming that in order to avoid project failures, the onshore and offshore teams from the vendor and client sides should work as an integrated project team. The CoP framework (1998) provide a sophisticated theoretical explanation of working as such an integrated project team, without being a team in the traditional sense (Powell et al., 2004). However, this study found that co-location without facilitation, even for extended periods, might not result in successful crosscultural knowledge sharing. Thus, four ways to facilitate cross-cultural knowledge sharing was proposed, when adopting the extended period of co-location strategy in software development offshoring. These suggestions may contribute to frameworks for guiding the co-location strategy in software development offshoring or supplement other studies' suggestions (Krishna et al., 2004; Persson et al., 2009) in managing cross-cultural knowledge sharing in distributed settings without co-location.

The study has implications for managers in software development with offshoring, who may consider extended co-location as a potentially costly but effective mitigation strategy for projects with high risk-exposure related to cross-cultural knowledge sharing. But also taking a critical stance towards the effect of initial short co-location on cross-cultural knowledge sharing practices at the level of ambition reflected in Wenger's (1998) indicators of CoP. Choosing an extended co-location period strategy, managers should carefully monitor and facilitate the emergence of knowledge sharing practices over time. Future research is however needed of what knowledge sharing practices can emerge over shorter periods of time when co-locating a project's crosscultural software developers, exploring the possibility of reducing the cost constraints of this strategy (Šmite et al., 2010). More research is also needed of why the four facilitators of cross-cultural knowledge sharing in collocated settings may be successful and how they should be implemented. Furthermore, future research is needed of the possibility for bringing CoP knowledge sharing practices from a collocated to a distributed setting. However, such research should consider the limitation of this study in the adopted conceptualization of CoP based on Wenger's (1998) indicators, emphasizing close relations created by sustained mutual engagement. The findings based on this conceptualization of CoP, may not be directly transferable to other conceptualizations of CoP (Cox, 2005) more suitable for exploring less tight knit community relations, as in Wenger's later work (Wenger et al., 2002).

\section{Conclusion}

This paper presents an investigation of the cross-cultural knowledge sharing challenge addressed by the co-location strategy in software development offshoring. A longitudinal case study of collocated Indian and Danish software developers revealed a positive change on 14 indicators of CoP over 10 months. While almost none of the 14 indicators of $\mathrm{CoP}$ had emerged after 2 weeks of co-location. The participants' 
contrasting with less successful use of collocated Indian developers in other projects, was synthesized into four distinctive facilitators of cross-cultural knowledge sharing: 1) shared office, 2) shared responsibility for tasks and problems, 3) shared prioritization of team spirit, and 4) a champion of social integration. This study helps understand the potential of the co-location strategy for mitigating the cross-cultural knowledge sharing challenge in software development offshoring, but also presents a critical stance towards the effect of shorter periods of co-location on cross-cultural knowledge sharing at project initiation.

\section{References}

Ardichvili, A.: Learning and Knowledge Sharing in Virtual Communities of Practice: Motivators, Barriers, and Enablers. Adv. Develop. Hum. Resour. 10, 541-554 (2008)

Bergiel, B.J., Bergiel, E.B., Balsmeier, P.W.: Nature of Virtual Teams: A Summary of their Advantages and Disadvantages. Management Research News 31, 99-110 (2008)

Boden, A., Avram, G., Bannon, L., et al.: Knowledge Sharing Practices and the Impact of Cultural Factors: Reflections on Two Case Studies of Offshoring in SME. Journal of Software: Evolution and Process 24, 139-152 (2012)

Brown, J.S., Duguid, P.: Organizational Learning and Communities-of-Practice: Toward a Unified View of Working, Learning, and Innovation. Organ. Sci. 2, 40-57 (1991)

Cavaye, A.L.M.: Case Study Research: A multi - faceted Research Approach for IS. Information Systems Journal 6, 227-242 (1996)

Connaughton, S.L., Shuffler, M.: Multinational and Multicultural Distributed Teams A Review and Future Agenda. Small Group Research 38, 387-412 (2007)

Cox, A.: What are Communities of Practice? A Comparative Review of Four Seminal Works. J. Inf. Sci. 31, 527-540 (2005)

Damian, D., Moitra, D.: Guest Editors' Introduction: Global Software Development: How Far have we Come? IEEE Software 23, 17-19 (2006)

Dibbern, J., Goles, T., Hirschheim, R., et al.: Information Systems Outsourcing: A Survey and Analysis of the Literature. ACM SIGMIS Database 35, 6-102 (2004)

Dibbern, J., Winkler, J., Heinzl, A.: Explaining Variations in Client Extra Costs between Software Projects Offshored to India. MIS Quarterly 32, 333-366 (2008)

Doh, J.P.: Offshore Outsourcing: Implications for International Business and Strategic Management Theory and Practice. Journal of Management Studies 42, 695-704 (2005)

Dubé, L., Bourhis, A., Jacob, R.: Towards a Typology of Virtual Communities of Practice. Interdisciplinary Journal of Information, Knowledge, and Management 1, 69-93 (2006)

Fielding, N.G., Lee, R.M.: Computer analysis and qualitative research. Sage Publications Limited, London (1998)

Gibson, C.B., Gibbs, J.L.: Unpacking the Concept of Virtuality: The Effects of Geographic Dispersion, Electronic Dependence, Dynamic Structure, and National Diversity on Team Innovation. Adm. Sci. Q. 51, 451-495 (2006)

Herbsleb, J.D., Moitra, D.: Global Software Development. IEEE Software 18, 16-20 (2001)

Hildreth, P., Kimble, C., Wright, P.: Communities of Practice in the Distributed International Environment. Journal of Knowledge Management 4, 27-38 (2000)

Iacovou, C.L., Nakatsu, R.: A Risk Profile of Offshore-Outsourced Development Projects. Commun ACM 51, 89-94 (2008) 
Kaiser, K.M., Hawk, S.: Evolution of Offshore Software Development: From Outsourcing to Cosourcing. MIS Quarterly Executive 3, 69-81 (2004)

Kimble, C., Hildreth, P.: Dualities, Distributed Communities of Practice and Knowledge Management. Journal of Knowledge Management 9, 102-113 (2005)

Klein, H.K., Myers, M.D.: A Set of Principles for Conducting and Evaluating Interpretive Field Studies in Information Systems. MIS Quarterly 23, 67-93 (1999)

Kotlarsky, J., Oshri, I.: Social Ties, Knowledge Sharing and Successful Collaboration in Globally Distributed System Development Projects. Eur. J. Inform. Syst. 14, 37-48 (2005)

Krishna, S., Sahay, S., Walsham, G.: Managing Cross-Cultural Issues in Global Software Outsourcing. Commun. ACM 47, 62-66 (2004)

Lamersdorf, A., Münch, J., Viso Torre, A.F., et al.: A rule - based Model for Customized Risk Identification and Evaluation of Task Assignment Alternatives in Distributed Software Development Projects. Journal of Software Maintenance and Evolution: Research and Practice 24, 661-675 (2012)

Lave, J., Wenger, E.: Situated learning: Legitimate peripheral participation. Cambridge university press, Cambridge (1991)

Martins, L.L., Gilson, L.L., Maynard, M.T.: Virtual Teams: What do we Know and Where do we Go from here? Journal of Management 30, 805-835 (2004)

Mishra, D., Mishra, A.: A Review of Non-Technical Issues in Global Software Development. Int. J. Comput. Appl. Technol. 40, 216-224 (2011)

Nakatsu, R.T., Iacovou, C.L.: A Comparative Study of Important Risk Factors Involved in Offshore and Domestic Outsourcing of Software Development Projects: A Two-Panel Delphi Study. Information \& Management 46, 57-68 (2009)

Persson, J.S.: Managing distributed software projects. PhD Thesis, Department of Computer Science, Aalborg University, Denmark (2010)

Persson, J.S., Mathiassen, L.: A Process for Managing Risks in Distributed Teams. IEEE Software 27, 20-29 (2010)

Persson, J.S., Mathiassen, L., Aaen, I.: Agile Distributed Software Development: Enacting Control through Media and Context. Inform. Syst. J. 22, 411-433 (2012)

Persson, J.S., Mathiassen, L., Boeg, J., et al.: Managing Risks in Distributed Software Projects: An Integrative Framework. IEEE T. Eng. Manage. 56, 508-532 (2009)

Philip, T., Wende, E., Schwabe, G.: Exploring Failures at the Team Level in OffshoreOutsourced Software Development Projects. In: Kotlarsky, J., Oshri, I., Willcocks, L.P. (eds.) Global Sourcing 2012. LNBIP, vol. 130, pp. 194-211. Springer, Heidelberg (2012)

Powell, A., Piccoli, G., Ives, B.: Virtual Teams: A Review of Current Literature and Directions for Future Research. ACM SIGMIS Database 35, 6-36 (2004)

Sakthivel, S.: Managing Risk in Offshore Systems Development. Commun ACM 50, 69-75 (2007)

Sakthivel, S.: Virtual Workgroups in Offshore Systems Development. Information and Software Technology 47, 305-318 (2005)

Sarker, S., Sahay, S.: Implications of Space and Time for Distributed Work: An Interpretive Study of US-Norwegian Systems Development Teams. Eur. J. Inform. Syst. 13, 3-20 (2004)

Siakas, K.V., Siakas, E.: The Need for Trust Relationships to Enable Successful Virtual Team Collaboration in Software Outsourcing. Int. J. Technol. Pol. Manage. 8, 59-75 (2008)

Singh, A., Nigam, A.R.K.: Risks Identification in an Offshore-Onshore Model Based IT Engagement. International Journal of Computer Applications 48, 31-41 (2012)

Šmite, D., Wohlin, C., Gorschek, T., et al.: Empirical Evidence in Global Software Engineering: A Systematic Review. Empirical Software Engineering 15, 91-118 (2010) 
Walsham, G.: Doing Interpretive Research. Eur. J. Inform. Syst. 15, 320-330 (2006)

Watson-Manheim, M.B., Chudoba, K.M., Crowston, K.: Perceived Discontinuities and Constructed Continuities in Virtual Work. Inform. Syst. J. 22, 29-52 (2012)

Wenger, E.: Communities of practice: Learning, meanings, and identity. Cambridge university press, New York (1998)

Wenger, E., McDermott, R.A., Snyder, W.: Cultivating communities of practice: A guide to managing knowledge. Harvard Business Press, Boston (2002)

Yalaho, A., Nahar, N.: Key Success Factors for Managing Offshore Outsourcing of Software Production using the ICT-Supported Unified Process Model: A Case Experience from Finland, India, Nepal and Russia. In: Proceedings of Technology Management for Global Economic Growth (PICMET), pp. 1-14 (2010)

Zigurs, I.: Leadership in Virtual Teams:-Oxymoron Or Opportunity? Organ. Dyn. 31, 339-351 (2003) 